Article

\title{
Sustainable Production of Japanese Eggplants in a Piedmont Soil in Rotation with Winter Cover Crops
}

\author{
Ramesh Ravella *, Muchha Reddy, Kurt Taylor and Ahmed Elobeid \\ North Carolina A \& T State University, 1601 E. Market Street, Greensboro, NC 27411, USA; \\ E-Mails: muchha@ncat.edu (M.R.); kotaylor@ncat.edu (K.T.); aelobeid@ncat.edu (A.E.) \\ * Author to whom correspondence should be addressed; E-Mail: rravella@ncat.edu; \\ Tel.: +1-336-285-4848; Fax: +1-336-334-7844.
}

Received: 18 December 2012; in revised form: 7 February 2013 / Accepted: 19 March 2013 / Published: 22 March 2013

\begin{abstract}
Eggplant is a popular vegetable consumed all over the world. Cover cropping is an efficient way of recycling nutrients and reducing inorganic fertilizer requirements to maintain the sustainability of the soil without affecting productivity and profitability. Eggplants (Solanum melongena) (Japanese varieties Hansel and Kamo) were grown in a Piedmont soil with two main treatments, cover crop (CC) and no cover crop (NC), and four sub-fertilizer treatments (T1: 0-0-0, T2: 56-28-112, T3: 84-56-168, and T4: 168-112-224 $\mathrm{N}-\mathrm{P}-\mathrm{K} \mathrm{kg} / \mathrm{ha}$ ), using four replications. The Hansel variety eggplant yield was significantly higher than the Kamo variety. Eggplant yields from CC treatments for both varieties were significantly higher $(p<0.001)$ than the yields from NC treatments. No significant difference was observed in the yields between T1 and T2 treatments, but the yields from T3 were significantly higher than T1 and T2 and yields from T4 were significantly higher than T3 yields. N released through mineralization of cover crop mixture ranged from $13.33 \mathrm{~g} / \mathrm{kg}$ at the beginning of the growing season and increased to $18.32 \mathrm{~g} / \mathrm{kg}$ at the end of the growing season. These results suggest that Japanese eggplants can be successfully grown in the Piedmont area of North Carolina in rotation with cover crops for higher yields.
\end{abstract}

Keywords: eggplants; cover crop; sustainable; Asian; ethnic markets; Piedmont; North Carolina 


\section{Introduction}

Sustainable production practices are not common in North Carolina's vegetable production. Vegetable crops are grown using conventional cultural practices and large amounts of fertilizer. These practices contribute to soil erosion and pollution of the surface and groundwater systems. Also, there is little or no information available on the production and potential yield of Asian vegetables on North Carolinian soils. Asian vegetable production can provide a dependable source of income for North Carolina's farmers. The tobacco industry in North Carolina is on the decline due to the elimination of tobacco quotas, the decrease in tobacco exports, and the increase in excise taxes on cigarette purchases. Traditional tobacco growing farmers are facing financial instability due to the decline of tobacco industry [1]. Many specialty crops are receiving greater attention as alternatives to tobacco. Growers are becoming successful with crops such as melons, hot peppers, sweet corn, medicinal herbs, and cut flowers, etc. At the same time, there is an increasing demand for Asian vegetables in the state due to an increase in the Asian population and Asian grocery stores. Currently, Asian vegetables that are sold in North Carolinian grocery stores are grown and shipped from Florida. Per capita consumption of eggplants in the US reached 0.9 lbs. between 2005 and 2010, and the increase in demand was met by both domestic production and import of eggplants [2]. Foreign Agricultural Service (FAS) of USDA estimates the export of eggplants from the US at $\$ 11.3$ million for a total of 10,125 tons [3]. In the year 2010 , the US imported 63,180 tons of eggplants, amounting to $\$ 64.4$ million, with more than 80 percent of the money going to Mexico and Canada [4]. Encouraging the farmers to grow Asian eggplants in the US will thus help to strengthen the economic status of farmers.

The use of sustainable, best-management practices can result in high yields and less environmental damage. Cover cropping is an efficient way of recycling nutrients and reducing inorganic fertilizer inputs to maintain the sustainability of the production system without affecting productivity. Legume cover crops when grown and incorporated into the soil, replenish the soils with nutrients, thereby reducing the need for chemical fertilizers [5,6]. Applied $\mathrm{N}$ is taken up by the crop in the field or immobilized in soil organic $\mathrm{N}$ pools, which is vulnerable to losses from volatilization, denitrification, and leaching [7]. Studies have found that leaving the ground bare between fall and spring cropping periods increases the risk of nutrients leaching into ground water. Nitrate nitrogen is among the most significant nutrients lost through this process due to greater solubility [8,9]. Winter cover crops help to improve soil fertility by taking up the nitrate nitrogen and preventing it from leaching into surface and ground waters [10]. Crop rotation is a powerful technique used in sustainable agriculture that does not involve inputs [11].

In addition to reducing $\mathrm{N}$ leaching and increasing soil organic matter, cover crops also play a major role in other aspects of environment and agriculture. Modifying current agricultural management practices as a means of sequestering $\mathrm{C}$ has been shown to be a relatively low-cost way to offset greenhouse gas emissions [12]. Increasing conservation practices in agriculture in the United States will enhance soil organic $\mathrm{C}$ and potentially increase $\mathrm{C}$ sequestration [13]. Weed suppression can be improved by increasing the abundance of cover crop biomass and residue [14,15]. Creamer et al. (1997) found that a cover crop mixture of hairy vetch, crimson clover, rye, and barley (Hordeum vulgare L.) produced high biomass levels and suppressed weed growth on par to a standard herbicide treatment [16]. Generally, residue from cover-crop biomass suppresses weed emergence early in the season, but does 
not provide full season weed control [17]. Keeping in view the heavy demand for Asian vegetables in North Carolina and the benefits of cover cropping in vegetable production, this experiment was designed to study the yield potential of Asian vegetables in the Piedmont area of North Carolina with cover crop rotation.

\section{Experimental Section}

\subsection{Site and Location}

The experiment was conducted at the North Carolina A \& T State University Farm in Guilford County, NC, USA. The soil is Mecklenburg Sandy Loam (fine, mixed, thermic Ultic Hapludalfs) and landscape at the experimental location is representative of many regions in the Piedmont (2\% slope) and southeastern United States. Cover crop (crimson clover + cereal rye) was planted in the fall of 2008 and mowed and incorporated into the soil in early April. Cover crop residues gradually decompose and release nutrients. Japanese eggplants (Hansel and Kamo) transplants were grown in plastic trays for 8-10 weeks in a greenhouse before transplanting in the field. Raised beds were prepared with drip lines and covered with a black plastic sheet prior to transplanting. Transplants were planted into the raised beds in April 2009. Row spacing of 5 feet between the beds and 2 feet between the transplants within a bed was adapted. The experimental design used was a split-split plot with two main treatments (cover crop: CC, no cover crop: NC) and four fertilizer treatments (T1: 0-0-0, T2: 56-28-112, T3: 84-56-168, and T4: 168-112-224 kg/ha of N-P-K) and two varieties (Hansel and Kamo) of eggplants in four replications. Each plot was divided into two sub plots and each sub plot has two beds for each variety of the eggplant.

The fertilizers were applied in split doses, one third of $\mathrm{N}$, all of $\mathrm{P}$ and one third of $\mathrm{K}$ were incorporated into the soil prior to transplanting. Remaining doses of $\mathrm{N}$ and $\mathrm{K}$ fertilizers were supplied to the eggplants through fertigation. The drip irrigation system was used to supply water to the eggplants. To determine the quantity of the nutrients released by the cover crop residues, a mesh bag study was conducted within these experiment plots. The decomposition study was conducted in the $\mathrm{CC}$ treatment plots. Cover crop residue was collected and placed inside the fiberglass mesh bags for the decomposition study. Each mesh bag had $30.8 \mathrm{~g}$ of cereal rye and $9.2 \mathrm{~g}$ of crimson clover residue. Mesh bags were sealed tight and placed in rows between the raised beds. Five mesh bags were placed in each of the four fertilizer treatment rows; each replication had 20 mesh bags for a total of 80 mesh bags. Mesh bags were placed at three-inch depth and 24 inches apart and collected at three-week intervals over the growing period of the vegetables. Mesh bags removed from the soil were rinsed with water carefully to remove the soil from the plant residues without losing any plant residues. Cleaned plant residues were oven dried for $48 \mathrm{~h}$ at $65^{\circ} \mathrm{C}$ and then weighed. Dried residues were then ground to pass through a 16-mesh sieve and analyzed for total $\mathrm{C}$ and $\mathrm{N}$ by dry combustion. Eggplants were harvested at marketable size and yields were recorded. Based on the treatments analysis of variance (ANOVA) results, recommendations can be made for development of alternative cropping systems with appropriate nutrient management, which can consequently reduce production costs, improve soil fertility, and limit nutrient losses to groundwater. 


\subsection{Statistical Analysis}

A split-split-plot design with four replications was used in this study. Yield data is analyzed using Statistical Analysis System (SAS, 2012) software [18]. Statistical significance was determined using Proc Anova at the 95\% confidence level.

\section{Results and Discussion}

The eggplant (Hansel and Kamo) yields varied greatly under all the treatments that were studied. The yields are presented in Table 1. Results show that significantly higher eggplant yields (Table 1) were obtained with the cover crop system in both varieties. Eggplant yields increased with increasing fertilizer rate. At $168 \mathrm{~kg} / \mathrm{ha}$ of $\mathrm{N}$ treatment, Hansel variety gave $94.5 \mathrm{t} / \mathrm{ha}$ under cover crop treatment and $73.9 \mathrm{t} / \mathrm{ha}$ under no cover crop treatment, and the Kamo variety's recorded yields were $77.3 \mathrm{t} /$ ha under cover crop treatment and $62.3 \mathrm{t} /$ ha under no cover crop treatment. The Hansel variety gave a higher yield compared to Kamo for all treatments (cover crop and fertilizer). Sabota and Sharma (1995) reported a yield of $41.3 \mathrm{t} / \mathrm{ha}$ of long eggplants (variety Taiwan Long) supplied with $89 \mathrm{~kg} / \mathrm{ha}$ of $\mathrm{N}$ in North Alabama [3]. Total production of eggplants in the year 2010 was 79,900 tons [2], resulting in an average yield of $29.43 \mathrm{t} / \mathrm{ha}$. The yield (Table 1) obtained in this study is significantly above the national average.

Table 1. Eggplant yield data for the two varieties under different fertilizer treatments and cover and no-cover crop systems. Hansel and Kamo are the eggplant varieties and NC stands for no cover crop and $\mathrm{C}$ for cover crop.

\begin{tabular}{ccccc}
\hline \multirow{2}{*}{ Fertilizer rate (N kg/ha) } & \multicolumn{4}{c}{ Yield t/ha } \\
\cline { 2 - 5 } & \multicolumn{2}{c}{ Hansel } & \multicolumn{3}{c}{ Kamo } \\
\hline & NC & C & NC & C \\
0 & 16.7 & 33.0 & 12.1 & 30.1 \\
56 & 23.3 & 58.2 & 20.6 & 41.4 \\
84 & 71.1 & 72.2 & 38.9 & 57.8 \\
168 & 73.9 & 94.5 & 62.3 & 77.3 \\
\hline
\end{tabular}

Statistical analysis of the yield data (Table 2) showed significant difference between the yields in cover crop and no cover crop treatments, fertilizer treatments and varieties. CC treatment gave significantly higher yields in both varieties of eggplants. As per varietal yields, Hansel produced significantly higher yields compared to Kamo. There was no significant difference between the yields for T1 and T2, but the eggplant yield from T3 was significantly higher than T1 and T2, and the eggplant yield from T4 was significantly higher than T3.

Residue decomposition was highest at $(80.30 \%)$ by September 5 th, the third sampling of the mesh bags which was significantly higher $(p \leq 0.05)$ compared to all other sampling dates. The mineralization of $\mathrm{N}$ from the crimson clover and cereal rye residue showed steady increase throughout the growing period. The $\mathrm{N}$ released through mineralization ranged from $13.33 \mathrm{~g} / \mathrm{kg}$ at the beginning of the growing season and increased to $18.32 \mathrm{~g} / \mathrm{kg}$ at the end of the growing season (Figure 1). 
Table 2. ANOVA table showing the significant differences among treatments and varieties in the eggplant study. CC stands for cover crop, TMT is treatment.

\begin{tabular}{lcccccc}
\hline \multicolumn{7}{c}{ ANOVA table for Hansel and Kamo eggplant varieties yield in t/ha } \\
\hline Variety & Term & DF & Sum of Squares & Mean Square & $F$-Value & $p$ Value \\
Hansel & CC & 1 & 2670 & 2670 & 8.92 & 0.0079 \\
& TMT & 3 & 17,929 & 5976 & 19.96 & $<0.0001$ \\
& Error & 18 & 5390 & 299 & & \\
& Total & 31 & 28,566 & & & \\
Kamo & CC & 1 & 2637 & 2637 & 17.95 & 0.0005 \\
& TMT & 3 & 10,945 & 3648 & 24.83 & $<0.0001$ \\
& Error & 18 & 2644 & 147 & & \\
& Total & 31 & 17,638 & & & \\
\hline
\end{tabular}

Figure 1. Graphical representation of cover crop residue decomposition at different sampling dates.

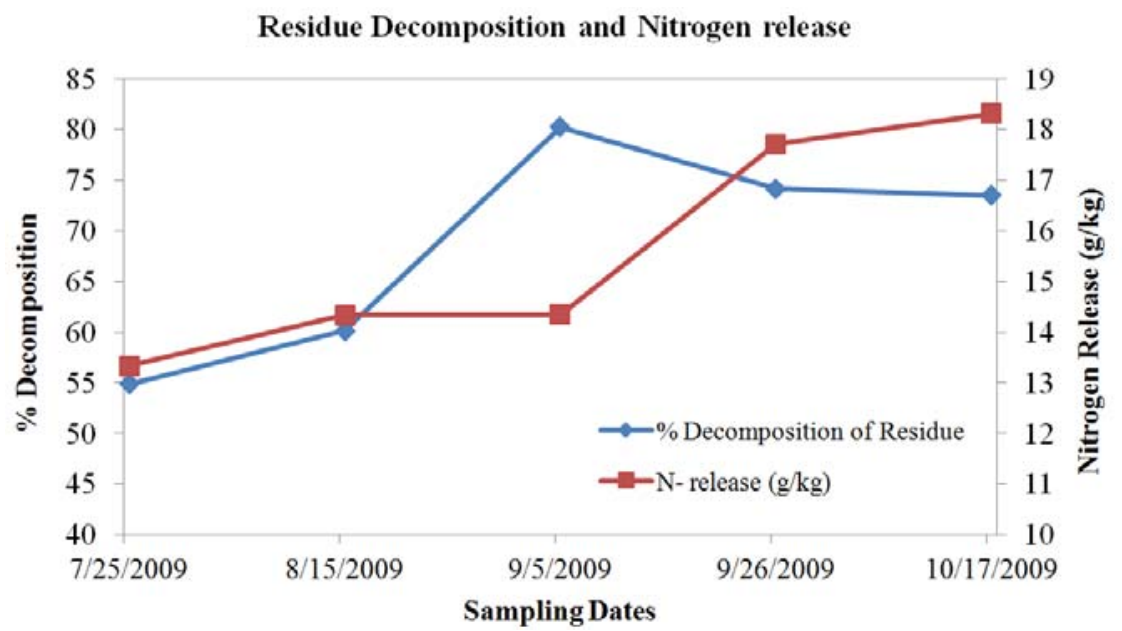

The longer the time residues were able to decompose, the greater was the mineralization of $\mathrm{N}$. Temperature consistently increased over the growing season with great consistency (Figure 2).

Figure 2. Air temperature range during the the eggplant growing period in the Piedmont region of North Carolina.

Avg. monthly temp $\left({ }^{\circ} \mathbf{F}\right)$

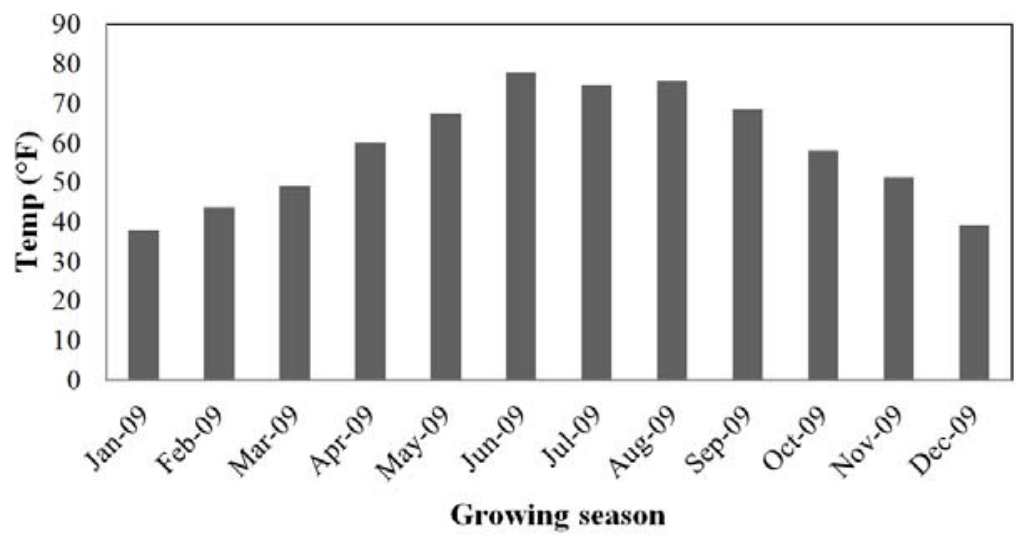


The growing season started with seasonal rainfall then in the middle of the growing season received little rainfall and then a period of high rainfall (Figure 3). The decrease in residue decomposition after the third sampling could be attributed to a flood-like situation in the field and limited microbial activity.

Figure 3. Annual precipitation during the experimental year in inches during the eggplant growing period in the Piedmont region of North Carolina.

Avg monthly precipitation (in)

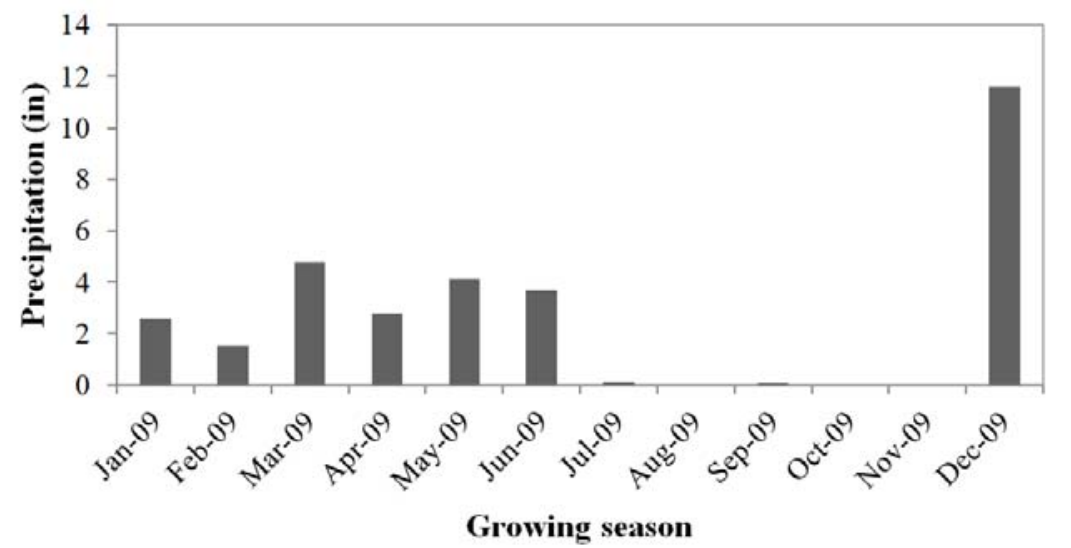

Demand for Asian vegetables like eggplants in the ethnic markets and supermarkets is increasing and the results from this study can help the farmers consider growing Asian vegetables as a viable alternative option. Crop diversification and sustainable farm income can be achieved by growing these eggplants. Eggplants yield from both varieties in this study were greater than the national average. This is a very encouraging result and farmers can benefit greatly from growing Asian vegetables such as Japanese eggplants. Further studies such as expanded marketability and revenue should be conducted to popularize the eggplant production among farmers. Local, regional and national demands should also be noted before engaging farmers in the production of these Asian vegetables on a larger scale. Mineralization of $\mathrm{N}$ from cover crops can supply some $\mathrm{N}$ to the crop and cut fertilization down if timed properly so that the crop can uptake the available nutrients at the peak of mineralization. Rates of $\mathrm{N}$ released were generally higher between September and October. Mineralization was rapid for the first nine weeks then a steady decline for the remaining six weeks of the study. Additional studies should be done to correlate $\mathrm{N}$ release from cover crops to meet or offset the need for fertilizer to the marketable crop. Soil moisture and temperature are critical in order to achieve a high decomposition and $\mathrm{N}$ release rate.

\section{Conclusions}

The experimental study of growing Asian vegetables (Japanese eggplants) in the Piedmont area of North Carolina demonstrated good potential for local farmers to grow Asian vegetables. Eggplant yields from cover crop (CC) treatment in this study gave higher yields for both varieties of eggplants than no cover crop (NC) treatment, which is an encouraging result to support sustainable growing of the Asian vegetables. Eggplant yields from T4 treatment were significantly higher than all other fertilizer treatments (T1, T2 and T3). The cover crop residue decomposition study demonstrated that the cover crop residues decompose in the piedmont soils and make nutrients available for plants and increase the 
yields. The data indicates the benefit of incorporating cover crops in the nutrient management practices to achieve higher yields.

\section{Acknowledgments}

The authors would like to thank the Evans-Allen Research Funding Program at NC A \& T State University for providing necessary funding and resources for this study. The authors would also like to thank NC A \& T State University Research farm personnel for helping with field work during the study.

\section{Conflict of Interest}

The authors declare no conflict of interest.

\section{References and Note}

1. North Carolina Agricultural Statistics, 2006. Available online: http://www.ncagr.com/stats/crop_ fld/fldjunyr.htm (accessed on 27 June 2006).

2. Economic Research Service (ERS). Vegetables and Melons Yearbook; ERS, United States Department of Agriculture (USDA): Washington, DC, USA, 2011.

3. Sabota, C.; Sharma, G. Production potential of exotic vegetables in the southeastern united state. $J$. Sustain. Agric. 1995, 7, 25-39.

4. Foreign Agricultural Service (FAS). Global Ag Trade System; FAS, United State Department of Agriculture (USDA): Washington, DC, USA, 2010.

5. Riedell, W.E.; Schumacher, T.; Evenson, P.D. Corn and soil fertility responses to crop rotation with low, medium or high inputs. Crop Sci. 1998, 38, 427.

6. Carefoot, J.M.; Janzen, H.H. Effect of straw management, tillage timing and timing of fertilizer nitrogen application on the crop utilization of fertilizer and soil nitrogen in an irrigated cereal rotation. Soil Tillage Res. 1997, 44, 195.

7. Cassman, K.G.; Dobermam, A.; Waters, D.T. Agroecosystems, nitrogen-use efficiency, and nitrogen management. AMBIO 2002, 31, 132-140.

8. Li, K.; Reddy, M.R. Nitrogen concentration in the soil water-atmosphere continuum in a sustainable cropping system. In Agronomy Abstracts; Agronomy Society of America: Anaheim, CA, USA, 1997; p. 271.

9. Johnson, P.A.; Shepherd, M.A.; Smith, P.N. The effects of crop husbandry on nitrate leaching from a shallow limestone soil growing a five course combinable crop rotation. Soil Use Manag. 1997, 13, 17.

10. Kuo, S.; Jellum, E.J. Influence of winter cover crop and residure management on soil nitrogen availability and corn. Agron. J. 2002, 94, 501-508.

11. Caproli, F.; Onnis, A. Validity of rotation as an effective agroecological principle for a sustainable agriculture. Agric. Ecosyst. Environ. 1992, 41, 101.

12. Antle, J.M. Sensitivity of carbon sequestration costs to soil carbon rates. Environ. Pollut. 2001, $116,413-422$. 
13. Uri, N.D. Conservation practices in United States agriculture and their impact on carbon sequestration. Environ. Monit. Assesst. 2001, 70, 323-344.

14. Mohler, C.L.; Teasdale, J.R. Response of weed emergence to rate of Vicia villosa Roth and Secale cereale L. residue. Weed Res. 1993, 33, 487-499.

15. Wicks, G.A.; Crutchfield, D.A.; Burnside, O.C. Influence of wheat straw mulch and metolachlor on corn growth and yield. Weed Sci. 1994, 42, 141-147.

16. Creamer, N.G.; Bennett, M.A.; Stinner, B.R. Evaluation of cover crop mixtures for use in vegetable production systems. HortScience 1997, 32, 866-870.

17. Teasdale, J.R. Contribution of cover crops to weed management in sustainable agricultural systems. J. Prod. Agric. 1996, 9, 475-479.

18. SAS, Version 9.2; SAS Institute Inc.: Cary, NC, USA, 2012.

(C) 2013 by the authors; licensee MDPI, Basel, Switzerland. This article is an open access article distributed under the terms and conditions of the Creative Commons Attribution license (http://creativecommons.org/licenses/by/3.0/). 